Orbis Tertius, vol. XXIV, $\mathrm{n}^{\circ}$ 30, e135, noviembre 2019-abril 2020. ISSN 1851-7811

Universidad Nacional de La Plata

Facultad de Humanidades y Ciencias de la Educación

Centro de Estudios deTeoría y Crítica Literaria

\title{
Teresa Basile, El desarme de Calibán: debates culturales y diseños literarios en la posdictadura uruguaya. Pittsburgh, Universidad de Pittsburgh, 2018, Nuevo Siglo, 324 páginas
}

Las páginas que siguen exponen un conjunto de reflexiones a partir de la lectura de El desarme de Calibán: Debates culturales y diseños literarios en la posdictadura uruguaya de Teresa Basile, con el fin no solo de reseñar el texto, sino también de ampliarlo en otras direcciones, consecuencia habitual de las investigaciones que resultan fermentales en el área de conocimiento que abordan. Dos partes componen el libro: la primera, dedicada a los debates culturales de la posdictadura uruguaya, y la segunda orientada al comentario crítico de algunos textos literarios del período que formaron parte del auge de la nueva novela histórica. Es la exposición de los desafíos a los que se enfrenta el estudio del campo intelectual de los años ochenta y noventa lo que ocupará mayormente la atención, y en especial los aportes en y desde el Uruguay al cuestionamiento de modelos anteriores de intelectuales latinoamericanos, aquellos que habían emulado la figura del guerrillero y la violencia de la acción armada. Una vez más, un personaje proveniente del canon literario más encumbrado de occidente (en este caso Calibán, el esclavo salvaje de La tempestad de William Shakespeare) articula una reflexión que remite a la simbología iniciada en 1971 por Roberto Fernández Retamar en su ensayo titulado precisamente Calibán, pero en esta oportunidad para analizar qué quedó en pie, qué en las sombras, de aquel intelectual armado después de la derrota. Se cumplen en el símbolo de Calibán las distintas operaciones que según Ángel Rama organizan cualquier proceso creativo de transculturación: pérdida, selección, redescubrimiento, incorporación.

Anteceden la llegada de este libro algunas publicaciones de la autora sobre literatura uruguaya reciente en el marco de los imaginarios sociales latinoamericanos posteriores a las utopías sesentistas. Una nómina de trabajos en la que se destaca la aparición de su tesis de doctorado en 2003, La novela histórica de la posdictadura en Uruguay (1985-1995), dirigida por Susana Zanetti, verdadero estadio anterior de una investigación que más tarde adquirió otros alcances a la vista. Porque si en 2003 Basile se había detenido específicamente en el auge de un género que adquirió sólida presencia en la literatura uruguaya hacia fines de la década del ochenta y comienzos de los noventa como fue la novela histórica, en El desarme de Calibán el análisis de un par de escritores destacados de este boom del género, acompañados de otras tantas referencias, resultará suficiente para cartografiar cómo la revisión de los imaginarios nacionales de la posdictadura operó en diseños literarios del período. ¡Bernabé, Bernabé! (1988) de Tomás de Mattos, que relataba el genocidio de los últimos charrúas en Salsipuedes y Mataojo durante 1831 y 1832, funcionó como mojón inaugural de la serie.

Junto a Bernabé, Bernabé!, ocupan el foco de atención otra novela de de Mattos, La fragata de las máscaras (1996) y de Amir Hamed Artigas Blues Band (1994) y Troya blanda (1996), este último autor como muestra de los límites del género y sus posibles fisuras. Lejos de la concepción de la literatura como reflejo, y en la apuesta por una mimesis devenida siempre en poiesis, Basile se propondrá "explorar un corpus literario que nos sirva para articular una imago del imaginario de la posdictadura uruguaya”, en el sentido en que 
José Lezama Lima entendió dicha categoría al explorar el barroquismo latinoamericano: "la literatura es capaz de reconvertir en un complejo haz de imágenes (imago) cada momento clave en la historia de un pueblo" (p. 83). El eje de la investigación en El desarme de Calibán integrará el estudio de la novela histórica a otros interrogantes: en qué devino el intelectual latinoamericano comprometido y revolucionario de los años sesenta (entre otros autores, Claudia Gilman, en su libro Entre la pluma y el fusil de 2003, realiza esta distinción conceptual), o en otras palabras, cómo se produjo el desarme de aquel intelectual simbolizado en el maldiciente Calibán, para Fernández Retamar genuina historia del continente, objeto de los sistemas opresivos en América Latina aunque sujeto de las luchas libertarias. Asimismo, en el Uruguay, cómo los ensayos de Hugo Achugar de los años noventa, La balsa de la Medusa (1992) o La biblioteca en ruinas (1994), intentaron explicar el desarme de los imaginarios nacionales, revolucionando para ello la propia retórica ensayística.

La lectura de El desarme de Calibán provoca un movimiento centrífugo y centrípeto respecto del Uruguay, ya que no pierde de vista el hecho de que los países del Cono Sur enfrentaron similares desafíos en sus respectivos procesos posdictatoriales, lo cual invita a estudiar los espacios de tránsito del Plan Cóndor, en una perspectiva de alcance internacional. No obstante, Basile se interesa por la respuesta particular del caso uruguayo en esas circunstancias comunes a la región: en lo político, por ejemplo, el desdibujamiento de los límites entre democracia y dictadura, ya que el golpe de Estado se concreta por intervención del presidente electo, Juan María Bordaberry, y el período dictatorial se cierra con acuerdos entre militares y partidos políticos. En lo social y lo cultural, la convivencia de diversos imaginarios nacionales que persistieron en la posdictadura y que en algunas oportunidades contribuyeron a frenar los impulsos renovadores: el imaginario batllista, los modelos culturales provenientes de las llamadas Generación del ‘ 45 y del '60, la épica tupamara, el propio imaginario legado por la dictadura y su fantasma del cuco verde, decisivo en el pacto de silencio que la flamante democracia entabló con sus antecesores militares. En esta línea, Fernando Butazzoni definió a la posdictadura, en un artículo publicado en Casa de las Américas en 1988, como una "cultura de la obediencia", una cultura "de la restauración", en la que los espacios que habían sido de resistencia durante el período dictatorial (el carnaval, las murgas, el teatro, el canto popular) se desdibujaban y desorientaban, temática y formalmente, frente a la llegada de la democracia tan ansiada.

En la vereda contraria a estos legados restauradores, gran parte de la sección de El desarme de Calibán dedicada a los debates culturales analiza los espacios dentro del Uruguay en los cuales diversas figuras del campo intelectual buscaron impulsar la construcción de una nueva matriz cultural que tomara distancia de modelos ya caducos, y en mayor o menor medida asociados a niveles de responsabilidad respecto de la violencia y la represión sufridas en los setentas, como el cuestionamiento de la lucha armada como vía de transformación social. Así, la colección Desafíos de Ediciones Trilce se funda en 1991 con el propósito de "desafiar a una reflexión abierta, pluridisciplinaria y centrada en el cambio necesario para lograr una sociedad justa y a su vez enfrentar el desafío que los cambios plantean”, según expresaba su director Pablo Harari en un paratexto de presentación que figuró junto a cada nuevo título de la colección. Asimismo Basile destaca la importancia de los autores nucleados en torno a Cuadernos de Marcha en su tercera época (de 1985 a 2001), publicación que la autora equipara al papel jugado en Argentina por la revista Punto de vista que dirigía Beatriz Sarlo, y por la Revista de Crítica Cultural chilena, a cargo de Nelly Richard. Apelando en general a una defensa del pluralismo cultural y de un concepto de democracia sustentado en el consenso y no ya opuesto al de marxismo, Basile expresa que "[e]stos movimientos de inestabilidad y recambio en la matriz cultural suscitaron un sentimiento de crisis que interpelaba los canales, modos y dispositivos capaces de reflexionar sobre los relatos nacionales" (p. 23), perspectiva contraria a otras, como la de Eugenia Allier Montaño en Batallas por la memoria (2010), que entendieron los años noventa, posteriores al referéndum que mantuvo vigente la Ley de Caducidad de la Pretensión Punitiva del Estado, como de afirmación del silencio y la desmemoria. Dicho de otro modo, al desarrollarse en paralelo una tendencia que imponía el mandato de la impunidad a través de la vigencia de la Ley 15.848 , y otra en cambio proveniente de algunos sectores del 
campo cultural que interrogaban a la historia reciente, Basile opta por indagar este segundo camino. Esto incluyó propuestas estéticas de algunos artistas de la llamada "generación dionisíaca”, en la que podría situarse a Hamed, generación que para Alfredo Alpini supuso "una juventud que captó el fracaso de la democracia y la ineficacia de la izquierda de los años sesenta”, que se opuso tanto a la derecha como a la izquierda, tal como expresó en un artículo titulado Una generación sin dioses (1996): "A la primera vertiente por dogmática y autoritaria, a la segunda, por intolerante, por insistir en la militancia disciplinada y por hacerles sacrificar el presente en vistas de un futuro inexistente". Más tarde, en 2005, Achugar consideraría que el camino de la "restauración democrática", unido a la denominación del período en términos de "posdictadura" había sido un fracaso, en la medida en que "cargado de buenas intenciones y de mucha nostalgia, indicaba a pesar de los pesares, la voluntad de pasar por encima de las transformaciones ocurridas". Ya no resultaba posible sostener aquel modelo nacional de cultura uruguaya de la clase media letrada en épocas de "culturas linyeras", como las definió Abril Trigo (1997).

El título elegido, El desarme de Calibán: Debates culturales y diseños literarios en la posdictadura uruguaya, articula tres pilares de la investigación. Por un lado los debates culturales, es decir el ensayo de interpretación nacional, de larga tradición en América Latina, y que en la posdictadura uruguaya tiene para Basile como figura clave de su reformulación a Achugar. Por otro los diseños literarios, o sea, la nueva novela histórica de este período. Dos géneros que, cada cual a su modo, coincidieron en revisar la historia nacional y desarmar a Calibán, lo cual remplazó la historia como progreso por otra que echara luz sobre las violencias silenciadas del pasado. Es decir, aquella lógica del amigo-enemigo, base de la llamada guerra sucia y de la teoría de los dos demonios, buscó para algunos intelectuales de la posdictadura ser sustituida por otra que apostaba por la democracia participativa, para la cual la pluralidad de posiciones y la heterogeneidad de los proyectos ya no constituían motivos de enfrentamientos y en cambio muestras del diálogo social y el respeto de las diversidades.

El desafío: transformar la historia dictatorial y la posterior perpetuación de la impunidad en objeto de estudio, y con ello asumir que la caída de los binarismos también implicaba analizar lo siniestro-familiar, esta inquietante pregunta: ¿de dónde salieron los torturadores? Los ejemplos de novelas históricas que aborda el libro de Basile plantean la necesidad de comprender el proceso identitario, poniendo en tela de juicio la existencia de una, o dos, versiones de la historia y dando protagonismo a voces disidentes, o a las mismas voces de siempre pero observadas desde nuevas ópticas. El género de la novela histórica tuvo un fuerte impacto político, y por encima de ello exigencias en el orden de lo ético; así lo demostró la polémica ante la publicación de ;Bernabé, Bernabé!, que provocó acalorados intercambios en el semanario Brecha y más tarde en Cuadernos de Marcha entre de Mattos, algunos críticos como Washington Lockhart, Ana Inés Larre Borges, Achugar y cartas de lectores durante los meses estivales de 1989. Se discutía la fidelidad a la historia, el tratamiento que la novela hacía de la figura del legendario héroe nacional José Artigas, el protagonismo otorgado a un personaje histórico como Bernabé Rivera, sobrino del primer presidente constitucional del Uruguay y asesino de los charrúas. La búsqueda por comprender lo siniestro-familiar se encuentra por ejemplo presente en un artículo de Larre Borges de 1988 publicado en Brecha, cercano a la publicación de la novela, para quien "[1] a ambigüedad de esos hombres" genocidas y fundadores de la identidad nacional "nos enfrenta a nuestras propias indecisiones frente a valores como el heroísmo, tantas veces preñado de brutalidad". Es decir, se le proponía al lector de iBernabé, Bernabé! desajustes e incomodidades alejados de maniqueísmos fáciles. $\mathrm{O}$ peor aún, se lo interrogaba acerca de cuánto había en su identidad oriental o uruguaya de aquellas víctimas y de aquellos victimarios.

Respecto de la reformulación del ensayo de interpretación nacional, Basile argumenta cómo el "intelectual experto" (p. 35) fue sustituyendo a su antecesor a favor de la revolución, contrario éste a la guetificación de la vida académica y defensor de la búsqueda de un público lector amplio, más interesado en el análisis político que en el orden de lo estético. "Ni subordinado a la política ni desinteresado de ella" (p. 35) será el lema que defina al ensayista de los años ochenta. En el caso de Achugar, habría que considerar que en su trayectoria, 
y en la de otros, el exilio supuso la inserción en universidades de distintos lugares del mundo que albergaron a los intelectuales latinoamericanos, nuevos lazos institucionales que propiciaron la reformulación de aquel intelectual atento a debates de interés general y análisis totalizadores por otro especializado y académico. Los años ochenta, iniciados para muchos fuera del Uruguay y de creciente esperanza en el retorno al país a medida que el acontecer político vislumbraba esa posibilidad, supusieron cambios en los modos de producción y circulación de los saberes, cambios en los protocolos y características del género ensayístico, en la figura de un intelectual cada vez más hermeneuta de la realidad y posmoderno en su defensa del hibridismo cultural y en su aceptación de la convivencia de mercados globales y locales, demócrata y comprometido no ya con la revolución armada sino con la defensa de los Derechos Humanos. Para Basile, el trayecto del desarme de Calibán se inicia con los ensayos de Fernández Retamar y su defensa del "intelectual armado", categoría que "no trata del grado de autonomía que adopte respecto a la esfera política sino de la intensidad con la que colabore en las tareas de la maquinaria simbólica de la violencia revolucionaria” (p. 112). La recorrida podría culminar en los ensayos de Achugar y el modelo del "intelectual solidario" que construye desde la diversidad, que ha abandonado el propósito de "traducir al otro", de "representar al otro", de "hacerse cargo de la escritura del otro", pues ya no se considera profeta de la verdad latinoamericana.

El discurso posmoderno toma distancia en este caso del ensayo entendido como organización más o menos improvisada de ideas personales, que no posee el sustento conceptual y metodológico propio de los géneros con retóricas académicas. Por el contrario, "la posmodernidad resulta más una capa de herramientas crítica y deconstructiva que un conjunto de signos y señas para describir o descifrar la emergencia de una sociedad posmoderna y sus nuevos sujetos, espacios y condiciones" (p. 32). Los ensayos de Achugar se escriben desde el balbuceo, término que repara en la problemática relación entre centro y periferia, incluso cuando esta última se constituye como objeto de conocimiento del primero. Ensayan la falta de sistematicidad, la interrogación, el fragmentarismo, la negación y la duda como estrategias retóricas de una enunciación polifónica. Si bien su temática no renuncia a la interpretación de los imaginarios nacionales, el propósito consiste en desarmar la primera persona del intelectual como la voz apta y lúcida para la interpretación de la realidad, y en cambio apostar por un yo desdoblado y múltiple, que evita las afirmaciones radicales, que duda de su propio decir.

En la línea teórico-crítica posestructuralista, practicada por Roland Barthes desde los años sesenta, el intelectual que "imprime y publica sus palabras", y que por ello se ubica para Barthes a medio tramo entre el profesor y el escritor, entre la palabra y la escritura, propone la puesta en escena del "artista libre", ese locutor que, rebelde a la autoridad de lo dicho, opta por discutir la claridad de la comunicación y "utiliza la irreversibilidad de la palabra como medio para trastornar su legalidad", tal como afirma en Escritores, intelectuales, profesores, texto de Barthes que se integró a Lo obvio y lo obtuso (2002). Los ensayos de Hamed, reunidos bajo el título Retroescritura (1998), plantean una posible poética desde la cual analizar los alcances del posestructuralismo teórico en la movida de los años ochenta y noventa uruguayos, marcada esta por el rock, los grafitis ciudadanos, las revistas under y los deseos de un parricidio difícil de concretar. Basile pone en diálogo estos textos con la ficción del autor, por ejemplo al afirmar que "[e]n Artigas Blues Band [...] se ejercita la retroescritura" (p. 272).

Por último, el tema planteado no atendería debidamente todas sus aristas de análisis si no se mencionara otra línea que se desarrolla en dirección contraria al giro lingüístico: aquella que, aunque también contrahegemónica, se asentó en la búsqueda de la verdad a través del profuso auge del género testimonial. Aunque excede los objetivos de su investigación, Basile menciona este aspecto al pasar (p. 33). Denunciar el terrorismo de Estado de la etapa dictatorial frente al silenciamiento instaurado en los ochenta por la oficialidad democrática constituyó el propósito de estas narraciones testimoniales, que contrapusieron al discurso oficial otras voces hasta ese momento relegadas o silenciadas, es decir las de los "salvados" en palabras de Primo Levi. ¿Alentó la ola testimonial la sustitución acrítica de una hegemonía por otra, o sea, el establecimiento de nuevos discursos dominantes, ahora de las víctimas, en los que otra vez el núcleo central fuera, como en el discurso del poder represivo, "la autovalidación excluyente de todo disenso"? Roberto Ferro planteó 
la paradoja de esta posible nueva hegemonía de las víctimas en La ficción: Un caso de sonambulismo teórico (1998). Cualquiera fuera la respuesta, la versión tupamara de la historia reciente transitó desde la épica sesentista, maniquea y politizada, hacia otra en la que cobró protagonismo la dimensión ética, centrada en la construcción de un relato de resistencia y lucha contra el autoritarismo que muchas veces buscó opacar las acciones anti-democráticas de los testimoniantes en el contexto de la lucha armada. 